\title{
Extraction Transformation Load
}

National Cancer Institute

\section{Source}

National Cancer Institute. Extraction Transformation Load. NCI Thesaurus. Code C142549.

A data integration process that involves collecting data from source systems, preparing and transforming the data according to business requirements, and loading them into a data warehouse. 